\title{
DNA methylation profiling in doxorubicin treated primary locally advanced breast tumours identifies novel genes associated with survival and treatment response
}

\author{
Emelyne Dejeux ${ }^{\dagger 1}$, Jo Anders Rønneberg ${ }^{+2,3}$, Hiroko Solvang 3,4, Ida Bukholm 33,5 , Stephanie Geisler ${ }^{6}$, Turid Aas 7 , \\ Ivo G Gut1, Anne-Lise Børresen-Dale2,3, Per Eystein Lønning6,8, Vessela N Kristensen²,3 and Jörg Tost*1
}

\begin{abstract}
Background: Breast cancer is the most frequent cancer in women and consists of a heterogeneous collection of diseases with distinct histopathological, genetic and epigenetic characteristics. In this study, we aimed to identify DNA methylation based biomarkers to distinguish patients with locally advanced breast cancer who may benefit from neoadjuvant doxorubicin treatment.

Results: We investigated quantitatively the methylation patterns in the promoter regions of 14 genes (ABCB1, ATM, BRCA1, CDH3, CDKN2A, CXCR4, ESR1, FBXW7, FOXC1, GSTP1, IGF2, HMLH1, PPP2R2B, and PTEN) in 75 well-described pretreatment samples from locally advanced breast cancer and correlated the results to the available clinical and molecular parameters. Six normal breast tissues were used as controls and 163 unselected breast cancer cases were used to validate associations with histopathological and clinical parameters.
\end{abstract}

Aberrant methylation was detected in 9 out of the 14 genes including the discovery of methylation at the FOXC1 promoter. Absence of methylation at the $A B C B 1$ promoter correlated with progressive disease during doxorubicin treatment. Most importantly, the DNA methylation status at the promoters of GSTP1, FOXC1 and ABCB1 correlated with survival, whereby the combination of methylated genes improved the subdivision with respect to the survival of the patients. In multivariate analysis GSTP1 and FOXC1 methylation status proved to be independent prognostic markers associated with survival.

Conclusions: Quantitative DNA methylation profiling is a powerful tool to identify molecular changes associated with specific phenotypes. Methylation at the ABCB1 or GSTP1 promoter improved overall survival probably due to prolonged availability and activity of the drug in the cell while FOXC1 methylation might be a protective factor against tumour invasiveness. FOXC1 proved to be general prognostic factor, while ABCB1 and GSTP1 might be predictive factors for the response to and efficacy of doxorubicin treatment. Pharmacoepigenetic effects such as the reported associations in this study provide molecular explanations for differential responses to chemotherapy and it might prove valuable to take the methylation status of selected genes into account for patient management and treatment decisions.

\section{Background}

Breast cancer, the most frequent cancer in women, consists of a heterogeneous collection of diseases with distinct his-

\footnotetext{
* Correspondence: tost@cng.fr

1 Laboratory for Epigenetics, Centre National de Génotypage, CEA - Institut de Génomique, Evry, France

+ Contributed equally

Full list of author information is available at the end of the article
}

topathological, genetic and epigenetic characteristics [1]. Conventional single parameters as well as gene expression signatures have been correlated to breast cancer prognosis. However, in contrast to endocrine therapy for which estrogen receptor expression is a predictive marker of response to therapy, we so far lack predictive factors for the selection of a chemotherapeutic regime except for ERBB2 (HER-2) 
overexpression advocating trastuzumab and increased anthracycline dosing [2].

While the contribution of genetic factors to breast carcinogenesis has long been recognized, it has become evident that epigenetic changes leading to transcriptional silencing of tumour suppressor genes are an at least equally contributing mechanism. In tumours a global loss of DNA methylation (hypomethylation) of the genome is observed at early stages of breast carcinogenesis which proceeds with increasing malignancy [3]. The overall decrease in DNA methylation is accompanied by a gene-specific increase of methylation (hypermethylation) of multiple promoter associated $\mathrm{CpG}$ islands leading to transcriptional silencing of genes involved in cell cycle arrest as well as apoptosis $[4,5]$.

The number of genes that has been identified to be aberrantly methylated in breast cancer is rapidly growing. Thus, high-throughput DNA methylation mapping technologies have the potential to identify distinct methylation signatures correlating with specific clinical stages and subtypes, but also to reveal the large heterogeneity of DNA methylation patterns within a tumour subgroup [6-9]. Considering the need to improve prognostication in breast cancer in general, and drug sensitivity prediction in particular [2], the examination of epigenetic gene alterations may improve our knowledge about the outcome and the response of a patient to given treatment.

Recently, we reported the haplotype structure to influence the level of DNA methylation of the GSTP1 promoter in breast cancers and to affect patient survival [10]. Here we broaden our analysis studying the methylation patterns in the promoter regions of 14 genes in 75 pre-treatment samples from locally advanced breast cancer by pyrosequencing. Genes were selected on the following basis: 1. previous reports of DNA methylation in breast tumours or at least breast cancer cell lines $(A B C B 1$ [11], ATM [12], BRCA1 [13], CDH3 [14], CDKN2A [13], ESR1 [15], GSTP1 [16], IGF2 [17], HMLH1 [13], PPP2R2B [18], PTEN [19]) or other cancers (CXCR4 [20]), 2. genes displaying variation in breast cancer gene expression profiles (FOXC1 [21]) and 3 . tumour suppressor genes known to harbour somatic mutations or be situated in frequently deleted regions in breast cancer but for which no DNA methylation analysis has so far been performed ( $F B X W 7$ [22]). In total $432 \mathrm{CpG}$ positions were investigated resulting in a data set of more than 37.000 quantitative epigenotypes, confirming previously reported associations and identifying novel DNA methylation based biomarkers associated with response to treatment and survival.

\section{Results}

We analyzed promoter methylation at $432 \mathrm{CpGs}$ in 14 genes giving rise to 37.000 epigenotypes (Figure 1A). The analysis included the DNA methylation in $A B C B 1$ (40
CpGs), ATM (56 CpGs), BRCA1 (46 CpGs), CDH3 (35 CpGs), CDKN2A (30 CpGs), CXCR4 (19 CpGs), ESR1 (50 CpGs) FBXW7 (31 CpGs), FOXC1 (14 CpGs), GSTP1 (21 CpGs), IGF2 (16 CpGs), MLH1 (24 CpGs), PPP2R2B (51 CpGs), and PTEN (39 CpGs). The six normal samples were unmethylated for all analyzed regions except for the highly methylated upstream region of $B R C A 1$, the differentially methylated region of the imprinted $I G F 2$ and the promoter region of ESRI (Figure 1A). Three amplification products in the $A B C B 1$ gene were found to be methylated in $70 \%$, $64 \%$ and $81 \%$ of the tumours. Methylation was found for CDKN2A (34\% of the samples), FOXC1 (50\%), PPP $2 R 2 B$ (56\% and 65\%), HMLHI (14\%), PTEN (22\% and 76\%) and GSTP1 (65\% and $83 \%)$. All samples were unmethylated for the transcription start site of BRCA1, ATM, CDH3, CXCR4 and $F B X W 7.10 \%$ of the samples exhibited a significant hypomethylation in the far upstream region of the $B R C A 1$ $\mathrm{CpG}$ island. Some methylation was found around the transcription start site for ESR1 but also within the normal breast samples. None of the genes displayed an age-dependent variation of DNA methylation at the analyzed loci.

Restricting the analysis to the loci with variable DNA methylation levels, no sample showed a completely normal methylation profile, $3 / 75$ tumours $(4 \%)$ showed abnormal methylation at one locus, $8(11 \%)$ at two loci, $4(5 \%)$ at three, $14(19 \%)$ at four and five loci, respectively, $16(21 \%)$ at six, $9(12 \%)$ at seven, $5(7 \%)$ at eight loci and two tumours $(3 \%)$ displayed aberrant methylation at nine loci. On average, five loci were thus aberrantly methylated in any sample. Methylation events at the different loci were not randomly distributed and independent from each other (Figure 1B). As expected, the methylation degrees of the different regions of the same gene were highly correlated if methylation was detected in all amplification products. Less expected, concomitant methylation was often found at different genes such as the $A B C B 1, F O X C 1$, GSTP1, $P P P 2 R 2 B, P T E N$ promoters identifying thus strongly correlated methylation events on different chromosomes (Figure 1B). Methylation at the estrogen receptor promoter did not correlate with any other gene. Pyrosequencing provides the advantage of yielding highly quantitative data on consecutive CpGs permitting analysis of the homogeneity of the methylation profiles. We identified for most genes some "core"-regions where DNA methylation levels correlated best with molecular and clinical parameters (see below). For most genes, these regions spanned - as expected - the transcription start sites.

\section{Correlation to expression profiles}

The observed methylation patterns were compared to the tumour subclasses as defined by microarray expression profiling [21]. Basal-like tumours generally showed a lower degree of methylation than the other subclasses (luminal A, luminal B, ERBB2 and normal-like). There was a trend for 

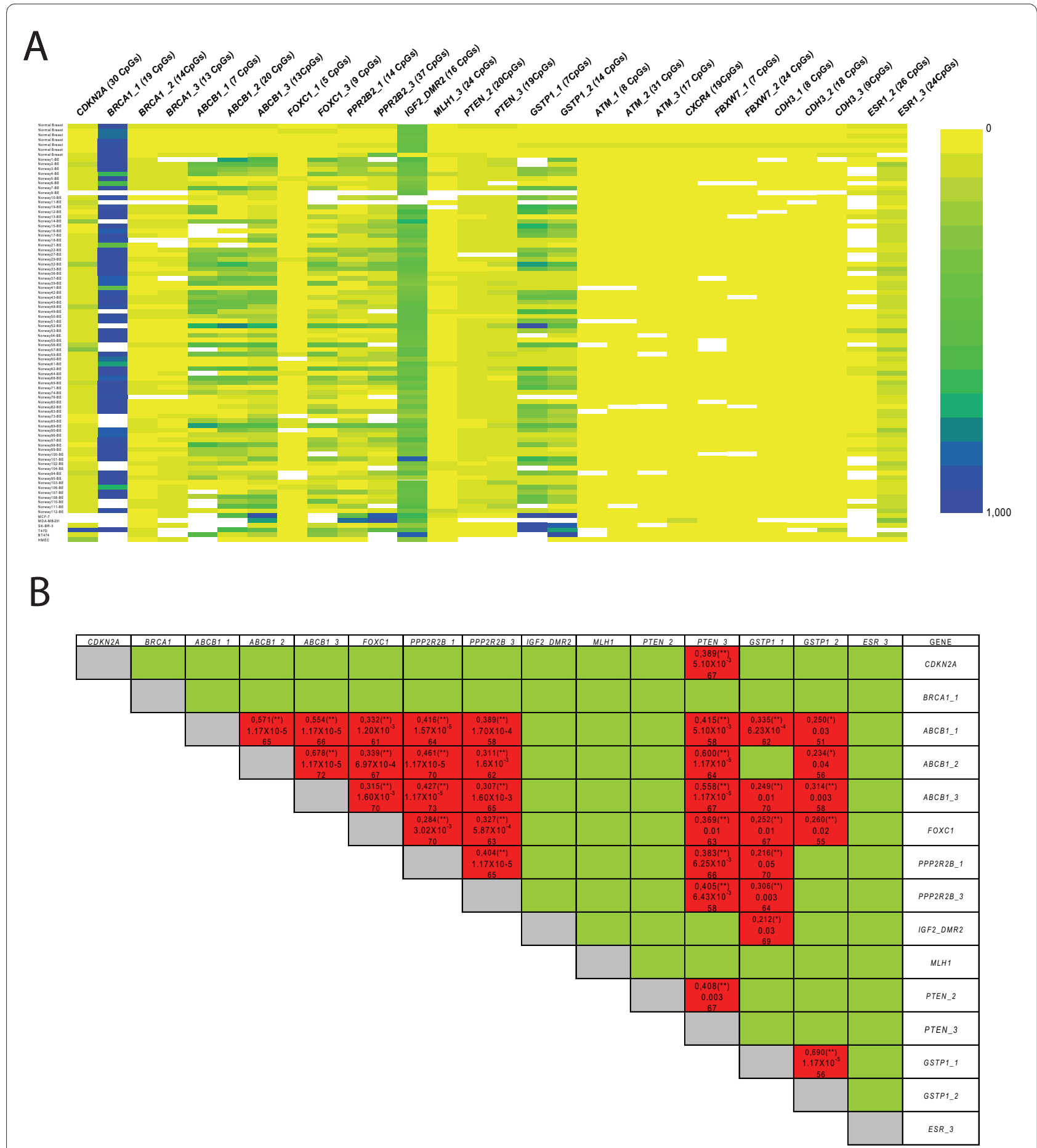

Figure 1 Summary of the methylation data. A) Summary of the average DNA methylation values in percentage for the analysis of the fourteen genes (x-axis) in the 75 breast cancer samples, six normal breast tissues (on top) and the six breast cancer cell lines (bottom lines). Absence of methylation over an amplification product is shown in yellow, complete methylation in dark blue; intermediate methylation degrees by the corresponding mixtures of the two colours. B) Nonparametric correlation of methylation levels between genes and between regions within the same gene. The first row and the last column contain the gene name or gene name followed by a number that indicate different genomic regions within the same gene (Additional File 5). Green squares have been assigned to correlations that are non significant. Red square correlations are significant after FDR correction (threshold 10\%). For each significant correlation 3 values are given from top to bottom: the correlation coefficient ( $R^{2}$ value), the $p$-value and the number of tested samples. 
the absence of methylation at $A B C B 1, F O X C 1, P P P 2 R 2 B$, and GSTPI in both the basal-like and normal-like tumours, while $I G F 2, M L H 1$ and $P T E N$ were hypomethylated in the basal-like tumours but not in the normal-like tumours. When analyzing the correlation between the expression level and the DNA methylation status of individual genes, genes with methylated promoters were almost exclusively not expressed, while unmethylated genes could be expressed as well as not be expressed weakening the correlation. The only significant correlation was obtained for GSTP1 ( $\mathrm{p}=0.003$, Correlation coefficient -0.47). Because of their association with survival (see below) we analyzed the expression levels of GSTP1, ABCBI and FOXCl by qRT-PCR (Additional File 1). qRT-PCR analysis correlated well with the microarray data (GSTP1: Pearson Corr. 0.661, $\mathrm{p}=0.003 ;$ FOXC1: Pearson Corr. 0.788, $\mathrm{p}<0.001 ; A B C B 1$ : Pearson Corr. $0.739, \mathrm{p}=0.015$ ). Consequently a significant negative correlation between expression as measured by TaqMan and methylation was found for GSTP1 (Spearman Correlation -0.567, $\mathrm{p}=0.018$ ), while expression and methylation for $F O X C 1$ and $A B C B 1$ were not significantly correlated $(\mathrm{p}=0.5$ and $\mathrm{p}=0.368$, respectively). Highly expressing genes were unmethylated for the respective promoter region of GSTP1 and FOXC1 and methylated promoters correlated with silenced expression. The weak correlation between expression and DNA methylation for FOXCl was due to the fact that the gene was already silenced in most tumours independent of its methylation status. Four samples were methylated for $A B C B 1$ but displayed high expression. This might be due to alternative usage of an upstream promoter [23] that is not under the control of the analyzed $\mathrm{CpG}$ island.

\section{Correlation with clinical parameters}

Methylation was analyzed in the discovery and validation cohorts both as a categorical variable, i.e. the presence/ absence of methylation at the respective promoter in association with the tumour characteristics, and as a quantitative variable investigating potential associations between the extent or the distribution of DNA methylation values and the analyzed clinical and molecular parameters (Additional File 2). Promoter methylation of $P P P 2 R 2 B$ in the pre-treatment sample was significantly associated with tumour grade $(p=0.019)$, whereby high-grade tumours were more frequently unmethylated than grade 1 and 2 tumours in the discovery cohort. The same was observed in the validation cohort of unselected breast cancers $(p=0.008)$. No association between methylation and tumour size was found. Estrogen receptor status positivity was associated with the presence and increased extent of methylation at the $P P P 2 R 2 B$ promoter in both the discovery $(\mathrm{p}=0.004)$ and the validation cohort $(\mathrm{p}=0.006)$. Samples unmethylated for $A B C B 1$ and those with increased levels of methylation in the differentially methylated region 2 of $I G F 2$ had more often overexpression of the ERBB2 oncogene ( $\mathrm{p}=0.005$ and $\mathrm{p}=0.007$, respectively), previously analyzed by immunohistochemistry [24]. No ERBB2 data was available for the validation cohort.

\section{Correlation with TP53 mutations}

We compared the observed DNA methylation profiles with the TP53 mutations status and found the lack of $A B C B 1$ and $P P P 2 R 2 B$ methylation to be associated with the presence of TP53 mutations in the discovery cohort $(\mathrm{p}=0.028$ and $\mathrm{p}=$ 0.010 , respectively) as well as in the validation cohort ( $p=$ 0.018 and $\mathrm{p}=0.001$, respectively). Tumours unmethylated for the middle region of the $A B C B 1 \mathrm{CpG}$ island were associated with mutations in the loop domains L2/L3 (p = 0.022 ), a region that has previously been shown to be associated with lack of response to doxorubicin based treatment. $P P P 2 R 2 B$ did not show any differential degree of methylation in function of the type of TP53 mutation.

\section{Survival analysis and response to treatment in the doxorubicin treated cohort}

The eight genes displaying variable DNA methylation patterns in a significant number of tumours $(A B C B 1, B R C A 1$, $C D K N 2 A, F O X C 1, G S T P 1, I G F 2, P P P 2 R 2 B$ and PTEN) within the discovery cohort were tested for association with survival by a logrank test. Breast cancer specific survival was significantly improved in patients with methylated promoters for $A B C B 1$, GSTP1 and FOXC1 ( $\mathrm{p}=0.004, \mathrm{p}=$ 0.004 and $\mathrm{p}=0.021$ respectively, Figure 2). Methylation of $A B C B 1$ and GSTP1 did also reach statistical significance after correction for multiple testing (Bonferroni correction, uncorrected $\mathrm{p}<0.00625$ ). Consistently, absence of methylation ( $\mathrm{p}=0.0076$, Additional File 2) in the $\mathrm{CpG}$ island of $A B C B 1$ was associated with poor response to doxorubicin (progressive disease) in the patient cohort treated with doxorubicin. In the validation cohort treated with different regimens, a significant difference in survival between methylated and unmethylated samples was confirmed for $F O X C l(\mathrm{p}=0.024)$ with patients unmethylated for the promoter region having again worse survival. Methylation of GSTP1 did not condition improved survival in the validation cohort of patients $(p=0.331)$. Similarly, only a trend for improved survival was observed for the methylation status of $A B C B 1(\mathrm{p}=0.070)$. The findings for GSTP1 and $A B C B 1$ might indicate a treatment specific effect on survival

Survival analysis in the doxorubicin treated cohort based on the logrank test indicated that TP53 mutation status $(\mathrm{p}=$ $0.001)$, grade $(\mathrm{p}=0.001)$ and the estrogen receptor status $(\mathrm{p}$ $=0.002$ ) could slightly better differentiate two survival groups in the analyzed sample collection when compared to the methylation status of the single genes $(A B C B 1(\mathrm{p}=$ 0.004), GSTPI $(\mathrm{p}=0.004)$ and FOXCl $(\mathrm{p}=0.021))$, while separation based on the progesterone receptor status and 


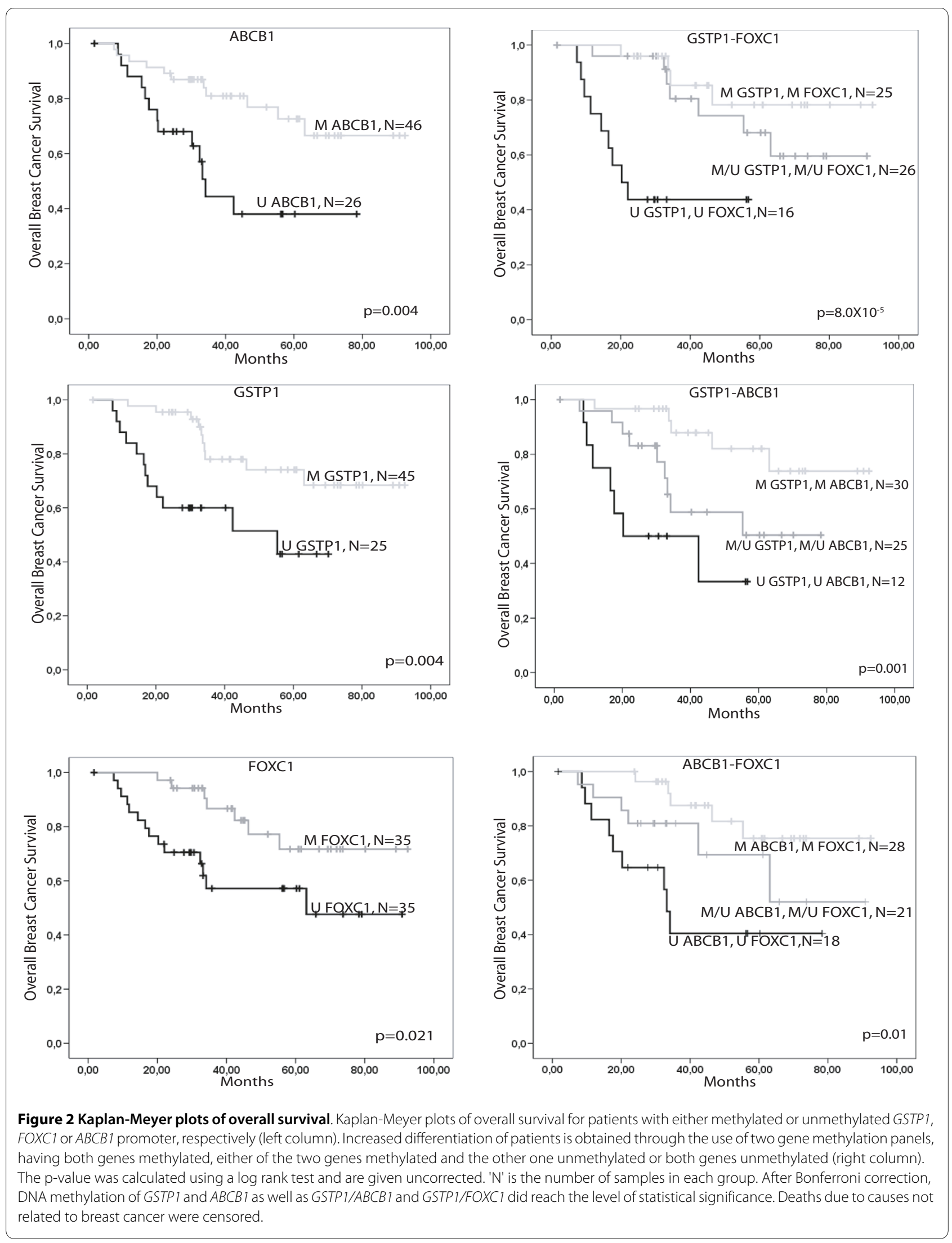


amplification of $E R B B 2$ or $T O P 2 A$ did not reach statistical significance. However, combination of two of the discovered DNA methylation markers further improved the distinction between doxorubicin treated patients having two, one or none of the genes methylated. No statistical difference on survival in function of the gene was found when comparing patients that had one of the two genes methylated and these were therefore combined for analysis. The best two-gene methylation pair comprised GSTP1 and FOXCl $\left(\mathrm{p}=8 \cdot 10^{-5}\right)$, followed by GSTP1 and $A B C B 1(\mathrm{p}=$ $0.001)$ and $A B C B 1$ and $F O X C 1(\mathrm{p}=0.01)$. Patients with all three genes methylated $(\mathrm{n}=20)$ had an improved survival compared to patients with all three genes unmethylated $(\mathrm{n}=$ $10, p=0.001)$. However, the separation lost its statistical significance when patients with mixed methylation patterns for all three genes were added to the analysis. We investigated if expression could be used as an alternative molecular measure to DNA methylation and divided samples in high versus low expression based on the mean expression values. The expression of GSTP1 was significantly associated with survival with patients with low levels of expression having as expected an improved survival $(\mathrm{p}=0.048)$. $F O X C 1(\mathrm{p}=0.247)$ and $A B C B 1(\mathrm{p}=0.181)$ were not significant but again showed improved survival for low expressing patients. When combining DNA methylation and expression, patients with an unmethylated GSTP1 promoter and expressed gene had poorer survival compared to patients with a methylated promoter that did not express GSTP1 $(\mathrm{p}=0.047)$. The same correlation was observed for $F O X C l(\mathrm{p}=0.045)$ and $A B C B 1(\mathrm{p}=0.022)$.

\section{Cox regression analysis of methylation markers and clinical variables in the doxorubicin treated cohort}

To identify significant parameters contributing to the observed differences in survival, Cox regression analysis was performed. The hazard ratio for each of the contributing factors was estimated separately (univariate analysis) or modelled together (multivariate analysis).

Univariate analysis identified the methylation status of $A B C B 1, F O X C 1$ and GSTP1 as significant predictors of overall survival. Estrogen receptor status as well as TP53 status and grade were also significant predictors of survival in univariate analysis (Table 1). To investigate if the methylation markers $A B C B 1, F O X C 1$ and GSTP1 were independent prognostic markers, we performed multivariate analysis with the methylation markers, grade, estrogen receptor status, TP53 status and stage. This analysis showed that the patients in this cohort with unmethylated GSTP1 (HR: 7.52, CI: 1.76-32.07, $\mathrm{p}=0.006$ ) and $\mathrm{FOXC1}$ (HR: 7.32, CI: $1.11-48.31, p=0.039)$ showed a higher risk of dying from breast cancer compared with patients methylated for the same genes (Table 2). The effect of $A B C B 1$ methylation on survival was no longer significant in the multivariate analysis probably due to its association with other histopathological factors (Additional File 2). Inclusion of the operation status (HR: 2.1, p = 0.452) in the multivariate analysis did slight reduce the hazard ratio for GSTP1 (HR: 5.8, $\mathrm{p}=0.028$ ) while increasing the HR for FOXCl (HR: 8.3, $\mathrm{p}=0.03$ ). The HR for the other parameters remained unchanged.

In order to identify the model with the minimum number of covariates that fitted best the experimental data, we used the Akaike information criterion. The best model with a reduced number of covariates explaining survival included the methylation status of $F O X C 1$ and GSTP1, stage, grade and estrogen receptor status (Additional File 3A). The best model with a minimum number of covariates where all covariates were independent of each other included ER, grade and the GSTPI methylation status (Additional File 3B). Using only a single covariate to model the survival of the patients by the AIC, the methylation status of any of the three different genes performed superior compared to the classical parameters with GSTP1 fitting the model best followed by FOXC1 and $A B C B 1$. To investigate the effect of the combination of the methylation status of two genes on survival, multivariate Cox regression analysis was again performed. Only the GSTP1/FOXC1 pair ( $\mathrm{p}=0.005$ and $\mathrm{p}$ $=0.013$ for the combination of either one or both genes being unmethylated, respectively) remained significant together with high grade $(\mathrm{p}=0.002)$ and ER status $(\mathrm{p}=$ 0.001) (data not shown).

\section{Discussion}

In the presented study we analyzed the methylation patterns in the promoter regions of fourteen genes in 75 pre-treatment samples from locally advanced breast cancers, six normal tissues and six widely used cell lines. Aberrant methylation events were detected in eleven out of the fourteen genes investigated. Discussion of the negative results can be found in the Additional File 4. Due to the highly quantitative nature of the employed pyrosequencing technology and its limit of detection ( $\sim 5 \%$ methylation in a sample) all methylation events detected in this study are occurring in a significant number of cells of a tumour sample and are therefore likely to have an impact on the characteristics of the tumour and - as pre-treatment samples were analyzed - might influence the response to a given chemotherapy.

The identified methylation patterns were non-random and some of the genes displayed a significant degree of comethylation pointing to a common epigenetic mechanism for their inactivation during tumourigenesis. There was a tendency for a lower frequency of aberrant promoter methylation in basal- and normal-like tumour samples. In a study recently published, basal-like tumour cell lines were characterized by the concomitant hypermethylation of a six gene panel (CDH1, CEACAM6, CST6, ESR1, LCN2, $S C N N 1 A$ ) [25]. However, using methylation in repetitive 


\begin{tabular}{|c|c|c|c|c|c|}
\hline \multirow[b]{2}{*}{ Covariate } & \multirow[b]{2}{*}{ Baseline } & \multicolumn{4}{|c|}{ Univariate } \\
\hline & & Coefficient & HR & $95,0 \% \mathrm{Cl}$ for $\mathrm{HR}$ & p-value \\
\hline Grade 2 & Grade 1 & 2.047 & 7.742 & $(1.012-59.228)$ & 0.049 \\
\hline Grade 3 & Grade 1 & 2.955 & 19.193 & $(2.455-150.003)$ & 0.005 \\
\hline $\mathrm{T} 3$ & $\mathrm{~T} 2$ & -0.18 & 0.982 & $(0.128-7.517)$ & 0.986 \\
\hline $\mathrm{T} 4$ & $\mathrm{~T} 2$ & 0.569 & 1.767 & $(0.228-13.717)$ & 0.586 \\
\hline N1 & No & 0.696 & 2.007 & $(0.696-5.783)$ & 0.197 \\
\hline N2 & No & 0.759 & 2.136 & $(0.714-6.383)$ & 0.174 \\
\hline M & Mo & 0.606 & 1.833 & $(0.683-4.918)$ & 0.229 \\
\hline Stage 3 & Stage2 & 0.852 & 2.344 & $(0.686-8.008)$ & 0.174 \\
\hline Stage 4 & Stage2 & 1.088 & 2.970 & $(0.708-12.463)$ & 0.137 \\
\hline ER & ER positive & 1.335 & 3.800 & $(1.566-9.223)$ & 0.003 \\
\hline PR & PR positive & 0.620 & 1.859 & $(0.800-4.318$ & 0.149 \\
\hline ErbB2 & ErbB2 positive & 0.965 & 2.624 & $(0.931-7.395)$ & 0.068 \\
\hline TP53 & Wild type TP53 & 1.230 & 3.423 & $(1.553-7.542)$ & 0.002 \\
\hline$A B C B 1 \_2$ & $\begin{array}{c}A B C B 1 \_2 \\
\text { Methylated }\end{array}$ & 1.147 & 3.147 & $(1.389-7.133)$ & 0.006 \\
\hline FOXC1_3 & $\begin{array}{c}\text { FOXC1_3 } \\
\text { Methylated }\end{array}$ & 1.030 & 2.802 & $(1.127-6.969)$ & 0.027 \\
\hline GSTP1_2 & $\begin{array}{c}\text { GSTP1_2 } \\
\text { Methylated }\end{array}$ & 1.215 & 3.369 & $(1.280-8.868)$ & 0.014 \\
\hline
\end{tabular}

Univariate survival analysis using the Cox regression model using the categorical methylation data. Positive hazard ratios indicate an increased risk of dying from breast cancer and are calculated for the different covariates in reference to the baseline as given in the 2nd column.

elements (LINE1/ALU) as a surrogate for genome-wide methylation levels, basal-like breast tumours are characterized by an overall loss of methylation (J. Tost, unpublished). The observed hypomethylation in the far upstream region of BRCA1 (green squares for $B R C A 1_{-} 1$ in Figure 1A) was found mainly in estrogen receptor negative tumours like the basal-like tumours further supporting the hypothesis that the genome-wide hypomethylation observed in breast cancer (as well as in any other cancer types) might be more pronounced in this tumour subclass. We did not detect hypermethylation of the $B R C A 1$ promoter (Amplicons BRCA1_2 and BRCA1_3 in Figure 1A), which might be explained by the absence of the rare metaplastic subtype of basal-like breast cancers, to which most methylation events of $B R C A 1$ seem to be restricted [26].

Since the tumour sub-classification based on gene expression is driven to a significant extent by expression of the estrogen receptor (ESRI), we studied its promoter methylation in normal samples as well as in a subset of the tumours. It has previously been shown that its degree of DNA methy- lation did not correlate well with hormone receptor status [27]. Our data confirms recently published data showing a certain degree of methylation of the estrogen receptor in tumours as well as in peritumoural/normal tissue but no difference in the quantitative distribution between normal and tumoural tissue [28].

Another studied gene, $P P P 2 R 2 B$ on $5 \mathrm{q} 31-\mathrm{q} 32$ encodes the regulatory subunit of the protein phosphates $2 \mathrm{~A}$ complex (PP2A) and has been proposed as a tumour suppressor gene candidate due to its negative control of cell growth and the high frequency of LOH in breast cancers [29]. An association of methylation levels to TP53 mutation status is reported here for the first time and might provide an alternative molecular mechanism for gene inactivation, as also the LOH has previously been associated with TP53 mutations [30]. The previously observed association with hormone receptor status [18] was also confirmed in our study. 


\begin{tabular}{|c|c|c|c|c|c|}
\hline \multirow[b]{2}{*}{ Covariate } & \multirow[b]{2}{*}{ Baseline } & \multicolumn{4}{|c|}{ Multivariate } \\
\hline & & Coefficient(bi) & $H R(\exp (b i)$ & $\begin{array}{c}95,0 \% \mathrm{Cl} \text { for } \\
\operatorname{Exp}(\mathrm{B})\end{array}$ & p-value \\
\hline Grade 2 & Grade1 & 1,67 & 5,30 & $(0,52-53,75)$ & 0,159 \\
\hline Grade 3 & Grade1 & 3,45 & 31,65 & $(2,47-404,27)$ & 0,008 \\
\hline ER & ER positive & 2,59 & 13,39 & $(2,62-68,50)$ & 0,002 \\
\hline TP53 & TP53 wild type & 1,75 & 5,73 & $(1,11-29,40)$ & 0,036 \\
\hline Stage 3 & Stage2 & 0,19 & 1,21 & $(0,20-7,03)$ & 0,833 \\
\hline Stage 4 & Stage2 & 2,00 & 7,38 & $(1,12-48,55)$ & 0,038 \\
\hline$A B C B 1 \_2$ & $\begin{array}{c}\text { Methylated } \\
A B C B 1 \_2\end{array}$ & $-1,13$ & 0,32 & $(0,05-2,20)$ & 0,247 \\
\hline FOXC1_3 & $\begin{array}{l}\text { Methylated } \\
\text { FOXC1_3 }\end{array}$ & 1,99 & 7,32 & $(1,11-48,31)$ & 0,039 \\
\hline GSTP1_2 & $\begin{array}{l}\text { Methylated } \\
\text { GSTP1_2 }\end{array}$ & 2,02 & 7,52 & $(1,76-32,07)$ & 0,006 \\
\hline
\end{tabular}

Multivariate survival analysis using the Cox regression model using the categorical methylation data. Positive hazard ratios indicate an increased risk of dying from breast cancer and are calculated for the different covariates in reference to the baseline as given in the $2 \mathrm{nd}$ column.

\section{Methylation and treatment response}

Our study is the first to show DNA methylation of the $A B C B 1 \mathrm{CpG}$ island to be associated with $E R B B 2$ amplification, TP53 mutation status, and response to doxorubicin treatment and overall survival in a doxorubicin-exposed cohort of primary breast cancers. Although the number of patients with progressive disease in the current study is limited and requires confirmation in other patient cohorts treated with anthracycline based treatment, there is good evidence that methylation of $A B C B 1$ plays an important role in the response to doxorubicin. Lack of methylation in the central part of the $A B C B 1 \mathrm{CpG}$ island was found to be associated with the TP53 mutation status and in particular with mutations in the L2/L3 DNA binding domain which have previously been associated with lack of response to treatment in the same patient cohort [24]. This finding further substantiates previous evidence indicating a link between TP53 and $A B C B 1$ [31]. How much this association contributes to the resistance to doxorubicin observed in some breast cancer patients needs further investigation. Expression of $A B C B 1$ has been shown to reduce intracellular doxorubicin concentration in cell cultures [32] and reexpression and promoter demethylation has been associated with resistance to anticancer drugs in vitro [33]. Although evidence from in vivo studies has been conflicting [34], a recent mouse model study lends support to the findings of our study by demonstrating that an increase of $A B C B 1$ expression the mice leads to the development of doxorubicin resistance that might be reversed by ABCB1 inhibitors such as tariquidar [35].

\section{Methylation and ERBB2 overexpression}

A possible link between ERBB2 and ABCB1 expression has been observed in a multidrug resistant MCF-7 cell line [36]. The amplification of the topoisomerase II $\alpha$ (TOP2A) gene significantly improves the outcome of anthracycline based adjuvant chemotherapy [37,38]. Interestingly, $T O P 2 A$ and $E R B B 2$ are co-amplified in our dataset $(\mathrm{p}=$ 0.008 , results not shown) warranting further investigation to explore the interaction between $A B C B 1$ methylation status and $T O P 2 A / E R B B 2$ amplification and how the combined effect of these proteins contributes to the drug resistance observed in anthracycline treatment regimens.

$I G F 2$ exerts its action on cellular growth through the insulin-like growth factor 1 receptor which interferes with anti-ERBB2 treatment through Akt signalling [39]. In murine cancer models methylation changes in the differentially methylated region 2 of $I G F 2$ have been associated with overexpression of $I G F 2$ [40], which in turn might activate IGF1R signalling and increase cell growth. Here we 
show that hypermethylation of the DMR2 of $I G F 2$ is specifically observed in ERBB2 positive breast cancers providing a new potential mechanistic link between IGF1R expression and ERBB2 status via $I G F 2$ methylation status.

\section{Methylation and survival}

We identify here the GSTP1 and FOXC1 methylation status as independent prognostic markers for breast cancer survival in a uniform patient cohort receiving neoadjuvant doxorubicin monotherapy prior to surgery and five years of tamoxifen for all ER positive patients according to a clinical study protocol [24]. FOXCl methylation status might be a general prognostic marker as it is able to separate patients in good and poor survival groups in the doxorubicin treated as well as in validation cohort while GSTP1 and $A B C B 1$ methylation status might be a predictive marker for doxorubicin monotherapy as the methylation status of these genes were not able to separate patients into survival groups in the validation cohort [2]. This is further supported by the fact that the hazard ratio for GSTP1 methylation decreased when the operation status was taken into account indicating that those tumours that increased further or at least did not regress during neoadjuvant treatment were more often unmethylated for GSTP1 while FOXC1 hazard ratio increased as would be expected for a treatment independent effect. $A B C B 1$ methylation status proved to be a marker for survival in the discovery cohort although it was not independent of other known markers in a multivariate model. The association with survival was less significant when the expression status instead of the DNA methylation status was analysed due to a strong correlation between DNA methylation and expression for GSTP1 only.

We confirm here a very recent report on the presence and extent of DNA methylation in the promoter of $\mathrm{FOXCl}$, a member of the forkhead protein family, many members of which are involved in the development and progression of cancer [41]. Mutations in FOXCl have recently been reported in a candidate re-sequencing approach of breast tumours [42] and $F O X C 1$ was found to be specifically hypomethylated and highly expressed in CD44+ compared to $\mathrm{CD} 24+$ stem cell progenitors, but no data correlating survival to the methylation patterns was presented [43]. The overexpression of the closely related $F O X C 2$ gene has been found to promote tumour metastasis and invasiveness [44].

CpG hypermethylation of the promoter region of the glutathione-S-transferase 1 (GSTPI) is a well established biomarker for hormone dependent cancers. Low activity of GSTP1 resulting from promoter hypermethylation may increase the effective therapeutic dose of the pharmacological agent due to lower conjugation and inactivation of the drug leading to increased survival. In support of this hypothesis it has been shown that GSTP1 expression correlates with doxorubicin resistance in breast cancer cell lines [45]. The observed improved survival has very recently been shown in samples in concordance with previous reports where the absence of GSTP1 protein expression correlated with improved survival in invasive breast cancer samples [46,47].

\section{Conclusions}

Methylation at the $A B C B 1$ or $G S T P 1$ promoter improved overall survival probably due to prolonged availability and activity of the drug in the cell while FOXC1 methylation might be a protective factor against tumour invasiveness.

The FOXC1 methylation status might be a widely applicable prognostic factor for breast cancer patients while the methylation status of $A B C B 1$ and GSTP1 might be a predictive factor for doxorubicin and perhaps anthracycline treatment in general. However, further studies are necessary to confirm the predictive value of these markers requiring additional patient cohorts treated with a doxorubicin/ anthracycline based monotherapy. Valuable time for treatment might be gained and the serious side-effects of a doxorubicin based regimen might be avoided taking the methylation status for treatment decisions into account. As the analyzed cohort consists of locally advanced primary tumours, it will be interesting to investigate the DNA methylation profiles also in T1/T2 and early stage breast cancer samples. Despite similar RNA expression profiles [21], some biological differences such as different frequencies of polymorphic alleles have recently been found to be enriched in advanced tumours [48]. Additional studies including prospective trials are required to fully evaluate the potential of these promising DNA methylation based markers to predict and monitor the efficacy of chemotherapy and to measure their impact on breast cancer management.

\section{Methods \\ Patient cohorts \\ Discovery cohort (Doxorubicin treated)}

Locally advanced breast cancer patients, admitted to the Haukeland University Hospital in Bergen (Norway) between 1991 and 1998 were part of a prospective study evaluating predictive factors for response to doxorubicin (n $=94$ ). Tumour DNA was available in sufficient quantity to perform methylation analyses from 75 of the patients. Tissue was obtained by an incisional biopsy prior to therapy and was immediately snap-frozen (liquid nitrogen in the theater) as previously reported [24]. DNA was isolated from snap frozen tumour tissue using phenol/chloroform extraction. The primary treatment consisted of weekly doxorubicin treatment $\left(14 \mathrm{mg} / \mathrm{m}^{2}\right)$ scheduled for 16 weeks. Patients with an operable tumour $(n=60)$ after neoadjuvant treatment had surgery followed by radiotherapy immediately after termination of the neoadjuvant chemotherapy. Eight patients had to be given radiotherapy prior to surgery due to local tumour extension, and seven patients were not 
eligible for surgery and were treated on an individual basis. Women with estrogen and/or progesterone positive tumours were all treated with tamoxifen (30 mg daily for 5 years). The main clinical characteristics of the analyzed 75 samples are given in Table 3 . The study protocol was approved by the local ethical committee, and the patients gave their informed consent.

\section{Validation cohort}

163 random, unselected breast cancer samples were used for the validation of the observed associations with clinicopathological factors. Clinical and molecular parameters such as histological grade $(\mathrm{n}=162)$, Estrogen receptor status $(\mathrm{n}=158)$ and TP53 mutation status $(\mathrm{n}=162)$ were available and used for validation. Follow-up/survival data was available for 87 of the patients. Tumour DNA extraction, bisulphite treatment and pyrosequencing analyses was performed using the same procedures as for the discovery dataset.

\section{Normal material}

DNA samples from normal breast tissue were included as control samples for methylation analysis. Normal breast tissue $(n=6)$ was obtained from women who underwent a biopsy of the mammary gland because of mammographic abnormalities, but for which histology confirmed the presence of only normal tissue.

\section{Cell lines}

The sample set was completed by immortalized human mammary epithelial cells (HMEC) and five widely used breast cancer cell lines (BT474, MCF-7, MDA-MB-231, SK-BR-3, and T47D).

\section{TP53 mutation, copy number and expression analyses}

Mutations in TP53 were analyzed in both the discovery and the validation cohorts by temporal temperature gradient electrophoresis (TTGE) followed by Sanger sequencing as previously described with primers covering regions (exons and introns) from exon 2-11 [24,49]. 50 of the doxorubicin treated tumours have been analyzed for gene expression using genome wide cDNA microarrays [21], and a subset of these tumours was analyzed for copy number alterations [50].

\section{Methylation assays}

Assays were optimized on unmethylated and methylated DNA as previously described [51]. DNA concentrations were determined using the Quant-i TM $^{\text {TM }}$ dsDA broad range assay kit (Invitrogen, Cergy Pontoise, France) and normalized to a concentration of $50 \mathrm{ng} / \mu \mathrm{l}$. One $\mu \mathrm{g}$ of DNA was bisulphite converted using the MethylEasy ${ }^{\mathrm{TM}}$ HT Kit for Centrifuge (Human Genetic Signatures, North Ryde, Australia) according to the manufacturer's instructions. Quantitative DNA methylation analysis of the bisulphite treated DNA was performed by pyrosequencing or - in case of several sequencing primers - by serial pyrosequencing [51].
Table 3: Molecular and clinical characteristics of the analyzed sample cohort

\begin{tabular}{|c|c|}
\hline Clinicopathological factors & Number of samples \\
\hline Median age at diagnosis & 65 (range 32-85) \\
\hline \multicolumn{2}{|l|}{ Histological grade } \\
\hline Grade 1 & $18(24 \%)$ \\
\hline Grade 2 & $38(50.7 \%)$ \\
\hline Grade 3 & $19(25.3 \%)$ \\
\hline \multicolumn{2}{|l|}{ Response } \\
\hline Progressive Disease & $7(9.5 \%)$ \\
\hline $\mathrm{PR}, \mathrm{MC}$ or SD & $67(90.5 \%)$ \\
\hline \multicolumn{2}{|l|}{ Tumor size } \\
\hline $\mathrm{T} 2$ & $3(4 \%)$ \\
\hline T3 & $47(62.7 \%)$ \\
\hline T4 & $25(33.3 \%)$ \\
\hline \multicolumn{2}{|l|}{ Lymph node metastasis } \\
\hline No & $25(33.3 \%)$ \\
\hline N1 & $29(38.7 \%)$ \\
\hline N2 & $21(28 \%)$ \\
\hline \multicolumn{2}{|l|}{ Distant metastasis } \\
\hline MO & $66(88.0 \%)$ \\
\hline M1 & $9(12 \%)$ \\
\hline \multicolumn{2}{|l|}{ Stage } \\
\hline Stage 2 & $18(24 \%)$ \\
\hline Stage 3 & $46(61 \%)$ \\
\hline Stage 4 & $11(15 \%)$ \\
\hline \multicolumn{2}{|l|}{ TP53 mutations } \\
\hline Wild type & 55 (73.3\%) \\
\hline Mutant & $20(26.7 \%)$ \\
\hline \multicolumn{2}{|l|}{ Estrogen receptor status } \\
\hline Positive & $65(86.7 \%)$ \\
\hline Negative & $10(13.3 \%)$ \\
\hline \multicolumn{2}{|l|}{$\begin{array}{l}\text { Progesteron receptor } \\
\text { status }\end{array}$} \\
\hline Positive & $58(77.3 \%)$ \\
\hline
\end{tabular}




\section{Table 3: Molecular and clinical characteristics of the analyzed sample cohort (Continued)}

$\begin{array}{ll}\text { Negative } & 17(22.7 \%) \\ \text { ErbB2 receptor status } & 11(25 \%) \\ \text { Positive } & 33(75 \%) \\ \text { Negative } & \\ & \\ \text { Survival } & 20(26.7 \%) \\ >5 \text { years } & 55(73.3 \%) \\ <5 \text { years } & \end{array}$

PR: partial response; MC: minimal change; SD: stable disease. Lymph node status was assessed clinically prior to neoadjuvant therapy and does not necessarily correspond to pathological lymph node status. In this context NO means that no enlarged nodes were felt prior to therapy. $\mathrm{N} 1$ corresponds to the presence of palpable and movable ipsilateral axillary lymph nodes suspicious of the presence of metastases while N2 corresponds to fixed ipsilateral axillary lymph nodes and thus very likely to the presence of tumours.

Regions of interest were amplified using $30 \mathrm{ng}$ of bisulfite treated human genomic DNA and 5 to 7.5 pmol of forward and reverse primer, one of them being biotinylated. Oligonucleotides for PCR amplification and pyrosequencing (Additional File 5) were synthesized by Biotez (Buch, Germany). Reaction conditions were $1 \times$ HotStar Taq buffer supplemented with $1.6 \mathrm{mM} \mathrm{MgCl}_{2}, 100 \mu \mathrm{M}$ dNTPs and 2.0 U HotStar Taq polymerase (Qiagen, Courtaboeuf, France) in a $25 \mu \mathrm{l}$ volume. The PCR program consisted of a denaturing step of $15 \mathrm{~min}$ at $95^{\circ} \mathrm{C}$ followed by 50 cycles of $30 \mathrm{~s}$ at $95^{\circ} \mathrm{C}, 30 \mathrm{~s}$ at the respective annealing temperature (Additional File 1) and $20 \mathrm{~s}$ at $72^{\circ} \mathrm{C}$, with a final extension of 5 $\min$ at $72^{\circ} \mathrm{C} .10 \mu \mathrm{l}$ of PCR product were rendered singlestranded as previously described [51] and 4 pmol of the respective sequencing primer (Additional File 1) were used for analysis. Quantitative DNA methylation analysis was carried out on a PSQ 96MD system with the PyroGold SQA Reagent Kit (Pyrosequencing) and results were analyzed using the Q-CpG software (V.1.0.9, Pyrosequencing AB).

\section{Expression analysis}

50 of the tumours have previously been analyzed for gene expression using genome wide cDNA microarrays [21]. For quantitative RT-PCR based expression analysis (TaqMan), cDNA was synthesized from $1 \mu \mathrm{g}$ of total RNA with random hexamers using the High Capacity cDNA Reverse Transcription Kit (Applied Biosystems, Foster City, Ca) in a final volume of $10 \mu \mathrm{l}$. Real-time PCR reactions were performed in triplicate in a final volume of $10 \mu 1$ using $50 \mathrm{ng}$ of cDNA and the TaqMan ${ }^{\circledR}$ Gene Expression Master Mix
(Applied Biosystems). TaqMan assays were all purchased from Applied Biosystems: Hs 00943351_g1 (GSTP1), Hs00184500 m1 (ABCBI) and Hs00559473 s1 (FOXC1). Human Breast Total RNA (Ambion, Austin, TX) was used to generate standard curves. PMMI (Hs00963626_m1) was used as endogenous control and the relative gene expression levels were determined using the standard curve method and normalized to $P M M 1$.

\section{Statistical analysis}

Differences in the presence of methylation were determined by a two-sided Fisher's test and $\chi^{2}$ tests. Samples were scored as methylated when the methylation degree exceeded the average methylation degree of the normal samples by two times the standard deviation of the normal samples and had at least a methylation degree of 5\% (detection limit of the technology). Odds ratio and 95\% confidence intervals were calculated. Differences in the distribution of methylation were assessed by the non-parametric Mann-Whitney or the Kruskal-Wallis test. Correlation between the methylation status of the different genes was calculated by the non-parametric Kendall's tau test. Pearson's coefficients were used to study the correlation between methylation and expression levels. All calculations were performed using Statistical Package for Science version 15.0. The Cox proportional hazards model was used to evaluate the effect sizes (given as hazard ratios), 95\% Confidence intervals (CI), regression coefficients and statistical significance of known clinicopathological features as well as the methylation status of selected genes. All covariates were treated as categorical variables. To investigate the relationship between multiple explanatory factors and survival, we used the Akaike information criterion (AIC) [52]. AIC evaluates the suitability of a selection of covariates in order to model the experimental observation and adds a penalty score with increasing number of parameters included in the model. The model with the minimum AIC is thus the model describing best the survival data. All possible combinations with respect to grade, stage, ER and TP53 mutation status as well as methylation of $A B C B 1, F O X C 1$ and GSTP1 respectively, were considered as covariates to the model. With $L$ being the likelihood function of the model and $k$ indicating the number of parameters of the model, the Akaike information criterion (AIC) is calculated by: $\mathrm{AIC}=-2 \log L+2 k$.

\section{Additional material}

Additional file 1 Correlation between DNA methylation and RNA expression for GSTP1, FOXC1 and ABCB1. Scatter plots showing the correlation between DNA methylation and RNA expression as measured by TaqMan for GSTP1, FOXC1 and ABCB1. 
Additional file 2 Associations of the presence/absence and degree of methylation and the clinical and molecular parameters. Associations of the presence/absence and degree of methylation and the clinical and molecular parameters of the samples by Fisher's exact test (2 categorical variables) or $x^{2}$ analysis (3 categorical variables) with odds ratio (OR) and 95\% Confidence interval (Cl) and their respective $\mathrm{p}$-value in the validation cohort. Statistical significance of the differences in the distribution of the degree of methylation is assessed by the non-parametric Mann-Whitney and Kruskal-Wallis test. Samples are called methylated if the methylation degree exceeded $5 \%$ and the average methylation degree of the healthy tissue samples plus at least two times the standard deviation of the healthy tissues.

Additional file 3 Best models to fit the observed survival data. A) Best models with a varying number of covariates to fit the observed survival data. B) Multivariate analysis of the best model with the minimum number of covariates. The presented model is the only one where all covariates are significant in multivariate analysis.

Additional file 4 Supplementary discussion. Discussion of negative results.

Additional file 5 PCR and pyrosequencing primers. Sequences of primers used for amplification and pyrosequencing reactions, Genbank accession numbers and nucleotides $(\mathrm{Nt})$ corresponding to the amplified fragments as well as the annealing temperatures for the respective PCR amplifications. CpGs are numbered in the order of appearance from the $5^{5}$ end of an amplification product. $Y=$ pyrimidine.

\section{Competing interests}

The authors declare that they have no competing interests.

\section{Authors' contributions}

ED and JAR performed laboratory experiments and data analyses and participated in writing of the manuscript. HS was involved in the statistical analyses. PEL, SG and TA were responsible for the doxorubicin treated patient cohort and clinical database management. ALBD and VNK were responsible for the validation cohorts and IB for the control samples. IGG, ALBD, VNK and JT initiated and designed the study. JT wrote the manuscript and VNK, PEL and ALBD participated in writing the manuscript. All authors have read and approved the final manuscript.

\section{Acknowledgements}

We thank Grethe I. Grenaker Alnæs for performing the TaqMan assays. This work was supported by the EU framework 6 integrated project MolPAGE (LSHG-CT-2004-512066) (JT, IGG), grant D-03067 from The Norwegian Cancer Society (VNK), grant 152004/150 from The Functional Genomics Program (FUGE) of the Norwegian Research Council (NFR) (VNK), the French-Norwegian cooperation program Aurora grant 15842WE (JAR, JT, VNK). JAR is a fellow at the Faculty Division The Norwegian Radium Hospital, University of Oslo.

\section{Author Details}

'Laboratory for Epigenetics, Centre National de Génotypage, CEA - Institut de Génomique, Evry, France, 2Department of Genetics, Institute for Cancer Research, Norwegian Radium Hospital, Rikshospitalet University Hospital Montebello, Oslo, Norway, ${ }^{3}$ Faculty of Medicine, University of Oslo, Norway, ${ }^{4}$ Institute for Medical Statistics, University of Oslo, Norway, ${ }^{5}$ Department of Surgery, Akerhus University Hospital, Lørenskog, Norway, ${ }^{6}$ Department of Oncology, Haukeland University Hospital, Bergen, Norway, ${ }^{7}$ Department of Surgery, Haukeland University Hospital, Bergen, Norway and 8 Section of Oncology, Institute of Medicine, University of Bergen, Norway

Received: 9 October 2009 Accepted: 25 March 2010

Published: 25 March 2010

\section{References}

1. Vargo-Gogola T, Rosen JM: Modelling breast cancer: one size does not fit all. Nat Rev Cancer 2007, 7:659-672

2. Lonning PE: Breast cancer prognostication and prediction: are we making progress? Ann Oncol 2007, 18(Suppl 8):viii3-7.

3. Ehrlich M: DNA methylation in cancer: too much, but also too little. Oncogene 2002, 21:5400-5413.
4. Laird PW: Cancer epigenetics. Hum Mol Genet 2005, 14(Spec No 1):R65-76.

5. Widschwendter $\mathrm{M}$, Jones PA: DNA methylation and breast carcinogenesis. Oncogene 2002, 21:5462-5482.

6. Yan PS, Perry MR, Laux DE, Asare AL, Caldwell CW, Huang TH: CpG island arrays: an application toward deciphering epigenetic signatures of breast cancer. Clin Cancer Res 2000, 6:1432-1438.

7. Parrella P, Poeta ML, Gallo AP, Prencipe M, Scintu M, Apicella A, Rossiello R, Liguoro G, Seripa D, Gravina C, Rabitti C, Rinaldi M, Nicol T, Tommasi S, Paradiso A, Schittulli F, Altomare V, Fazio VM: Nonrandom distribution of aberrant promoter methylation of cancer-related genes in sporadic breast tumors. Clin Cancer Res 2004, 10:5349-5354.

8. Korshunova Y, Maloney RK, Lakey N, Citek RW, Bacher B, Budiman A, Ordway JM, McCombie WR, Leon J, Jeddeloh JA, McPherson JD: Massively parallel bisulphite pyrosequencing reveals the molecular complexity of breast cancer-associated cytosine-methylation patterns obtained from tissue and serum DNA. Genome Res 2008, 18:19-29.

9. Ordway JM, Budiman MA, Korshunova Y, Maloney RK, Bedell JA, Citek RW, Bacher B, Peterson S, Rohlfing T, Hall J, Brown R, Lakey N, Doerge RW, Martienssen RA, Leon J, McPherson JD, Jeddeloh JA: Identification of novel high-frequency DNA methylation changes in breast cancer. PLOS ONE 2007, 2:e1314

10. Ronneberg JA, Tost J, Solvang HK, Alnaes GI, Johansen FE, Brendeford EM, Yakhini Z, Gut IG, Lonning PE, Borresen-Dale AL, Gabrielsen OS, Kristensen VN: GSTP1 promoter haplotypes affect DNA methylation levels and promoter activity in breast carcinomas. Cancer Res 2008, 68:5562-5571.

11. David GL, Yegnasubramanian S, Kumar A, Marchi VL, De Marzo AM, Lin X, Nelson WG: MDR1 promoter hypermethylation in MCF-7 human breast cancer cells: changes in chromatin structure induced by treatment with 5-Aza-cytidine. Cancer Biol Therap 2004, 3:540-548.

12. Vo QN, Kim WJ, Cvitanovic L, Boudreau DA, Ginzinger DG, Brown KD: The ATM gene is a target for epigenetic silencing in locally advanced breast cancer. Oncogene 2004, 23:9432-9437.

13. Esteller M, Corn PG, Baylin SB, Herman JG: A gene hypermethylation profile of human cancer. Cancer Res 2001, 61:3225-3229.

14. Paredes J, Albergaria A, Oliveira JT, Jeronimo C, Milanezi F, Schmitt FC: Pcadherin overexpression is an indicator of clinical outcome in invasive breast carcinomas and is associated with $\mathrm{CDH} 3$ promoter hypomethylation. Clin Cancer Res 2005, 11:5869-5877.

15. Lapidus RG, Nass SJ, Butash KA, Parl FF, Weitzman SA, Graff JG, Herman JG, Davidson NE: Mapping of ER gene CpG island methylation-specific polymerase chain reaction. Cancer Res 1998, 58:2515-2519.

16. Esteller M, Corn PG, Urena JM, Gabrielson E, Baylin SB, Herman JG: Inactivation of glutathione S-transferase P1 gene by promoter hypermethylation in human neoplasia. Cancer Res 1998, 58:4515-4518.

17. Issa JP, Vertino PM, Boehm CD, Newsham IF, Baylin SB: Switch from monoallelic to biallelic human IGF2 promoter methylation during aging and carcinogenesis. Proc Natl Acad Sci USA 1996, 93:11757-11762.

18. Keen JC, Garrett-Mayer E, Pettit C, Mack KM, Manning J, Herman JG, Davidson NE: Epigenetic regulation of protein phosphatase $2 \mathrm{~A}$ (PP2A), lymphotactin (XCL1) and estrogen receptor alpha (ER) expression in human breast cancer cells. Cancer Biol Therap 2004, 3:1304-1312.

19. Garcia JM, Silva J, Pena C, Garcia V, Rodriguez R, Cruz MA, Cantos B, Provencio M, Espana P, Bonilla F: Promoter methylation of the PTEN gene is a common molecular change in breast cancer. Genes Chromosomes Cancer 2004, 41:117-124.

20. Mori T, Kim J, Yamano T, Takeuchi H, Huang S, Umetani N, Koyanagi K, Hoon DS: Epigenetic up-regulation of C-C chemokine receptor 7 and C$\mathrm{X}-\mathrm{C}$ chemokine receptor 4 expression in melanoma cells. Cancer Res 2005, 65:1800-1807

21. Sorlie T, Perou CM, Tibshirani R, Aas T, Geisler S, Johnsen H, Hastie T, Eisen $M B$, van de Rijn $M$, Jeffrey SS, Thorsen T, Quist $H$, Matese JC, Brown PO, Botstein D, Lonning PE, Borresen-Dale AL: Gene expression patterns of breast carcinomas distinguish tumor subclasses with clinical implications. Proc Natl Acad Sci USA 2001, 98:10869-10874.

22. Akhoondi S, Sun D, Lehr N von der, Apostolidou S, Klotz K, Maljukova A, Cepeda D, Fiegl H, Dafou D, Marth C, Mueller-Holzner E, Corcoran M, Dagnell M, Nejad SZ, Nayer BN, Zali MR, Hansson J, Egyhazi S, Petersson F, Sangfelt $\mathrm{P}$, Nordgren $\mathrm{H}$, Grander D, Reed SI, Widschwendter M, Sangfelt O, Spruck C: FBXW7/hCDC4 is a general tumor suppressor in human cancer. Cancer Res 2007, 67:9006-9012. 
23. Raguz S, Tamburo De Bella M, Tripuraneni G, Slade MJ, Higgins CF, Coombes RC, Yague E: Activation of the MDR1 upstream promoter in breast carcinoma as a surrogate for metastatic invasion. Clin Cancer Res 2004, 10:2776-2783.

24. Geisler S, Lonning PE, Aas T, Johnsen H, Fluge O, Haugen DF, Lillehaug JR, Akslen LA, Borresen-Dale AL: Influence of TP53 gene alterations and cerbB-2 expression on the response to treatment with doxorubicin in locally advanced breast cancer. Cancer Res 2001, 61:2505-2512.

25. Roll JD, Rivenbark AG, Jones WD, Coleman WB: DNMT3b overexpression contributes to a hypermethylator phenotype in human breast cancer cell lines. Mol Cancer 2008, 7:15.

26. Turner NC, Reis-Filho JS, Russell AM, Springall RJ, Ryder K, Steele D, Savage K, Gillett CE, Schmitt FC, Ashworth A, Tutt AN: BRCA1 dysfunction in sporadic basal-like breast cancer. Oncogene 2007, 26:2126-2132.

27. Widschwendter M, Siegmund KD, Muller HM, Fiegl H, Marth C, Muller-

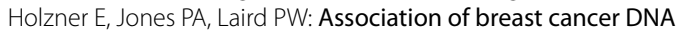
methylation profiles with hormone receptor status and response to tamoxifen. Cancer Res 2004, 64:3807-3813.

28. Feng W, Shen L, Wen S, Rosen DG, Jelinek J, Hu X, Huan S, Huang M, Liu J, Sahin AA, Hunt KK, Bast RC Jr, Shen Y, Issa JP, Yu Y: Correlation between CpG methylation profiles and hormone receptor status in breast cancers. Breast Cancer Res 2007, 9:R57.

29. Johannsdottir HK, Jonsson G, Johannesdottir G, Agnarsson BA, Eerola H, Arason A, Heikkila P, Egilsson V, Olsson H, Johannsson OT, Nevanlinna H, Borg A, Barkardottir RB: Chromosome 5 imbalance mapping in breast tumors from BRCA1 and BRCA2 mutation carriers and sporadic breast tumors. Int J Cancer 2006, 119:1052-1060.

30. Jain AN, Chin K, Borresen-Dale AL, Erikstein BK, Lønning PE, Kaaresen R, Gray JW: Quantitative analysis of chromosomal CGH in human breast tumors associates copy number abnormalities with $\mathrm{p} 53$ status and patient survival. Proc Natl Acad Sci USA 2001, 98:7952-7957.

31. Nordgard SH, Ritchie MD, Jensrud SD, Motsinger AA, Alnaes Gl, Lemmon G, Berg M, Geisler S, Moore JH, Lonning PE, Borresen-Dale AL, Kristensen VN: ABCB1 and GST polymorphisms associated with TP53 status in breast cancer. Pharmacogenet Genomics 2007, 17:127-136.

32. Shen F, Chu S, Bence AK, Bailey B, Xue X, Erickson PA, Montrose MH, Beck WT, Erickson LC: Quantitation of doxorubicin uptake, efflux, and modulation of multidrug resistance (MDR) in MDR human cancer cells. J Pharmacol Exp Ther 2008, 324:95-102.

33. Kantharidis P, El-Osta A, deSilva M, Wall DM, Hu XF, Slater A, Nadalin G Parkin JD, Zalcberg JR: Altered methylation of the human MDR1 promoter is associated with acquired multidrug resistance. Clin Cancer Res 1997, 3:2025-2032

34. Leonessa F, Clarke R: ATP binding cassette transporters and drug resistance in breast cancer. Endocr Relat Cancer 2003, 10:43-73.

35. Pajic M, lyer JK, Kersbergen A, Burg E van der, Nygren AO, Jonkers J, Borst $P$, Rottenberg S: Moderate increase in Mdr1a/1b expression causes in vivo resistance to doxorubicin in a mouse model for hereditary breast cancer. Cancer Res 2009, 69:6396-6404.

36. Misra S, Ghatak S, Toole BP: Regulation of MDR1 expression and drug resistance by a positive feedback loop involving hyaluronan, phosphoinositide 3-kinase, and ErbB2. J Biol Chem 2005, 280:20310-20315.

37. Coon JS, Marcus E, Gupta-Burt S, Seelig S, Jacobson K, Chen S, Renta V, Fronda G, Preisler HD: Amplification and overexpression of topoisomerase Ilalpha predict response to anthracycline-based therapy in locally advanced breast cancer. Clin Cancer Res 2002, 8:1061-1067.

38. Tanner M, Isola J, Wiklund T, Erikstein B, Kellokumpu-Lehtinen P, Malmstrom P, Wilking N, Nilsson J, Bergh J: Topoisomerase Ilalpha gene amplification predicts favorable treatment response to tailored and dose-escalated anthracycline-based adjuvant chemotherapy in HER-2/ neu-amplified breast cancer: Scandinavian Breast Group Trial 9401. J Clin Oncol 2006, 24:2428-2436.

39. Harris LN, You F, Schnitt SJ, Witkiewicz A, Lu X, Sgroi D, Ryan PD, Come SE, Burstein HJ, Lesnikoski BA, Kamma M, Friedman PN, Gelman R, Iglehart JD, Winer EP: Predictors of resistance to preoperative trastuzumab and vinorelbine for HER2-positive early breast cancer. Clin Cancer Res 2007, 13:1198-1207.

40. Fontaniere S, Tost J, Wierinckx A, Lachuer J, Lu J, Hussein N, Busato F, Gut I, Wang ZQ, Zhang CX: Gene expression profiling in insulinomas of Men1 beta-cell mutant mice reveals early genetic and epigenetic events involved in pancreatic beta-cell tumorigenesis. Endocr Relat Cancer 2006, 13:1223-1236.

41. Myatt SS, Lam EW: The emerging roles of forkhead box (Fox) proteins in cancer. Nat Rev Cancer 2007, 7:847-859.

42. Chanock SJ, Burdett L, Yeager M, Llaca V, Langerod A, Presswalla S, Kaaresen R, Strausberg RL, Gerhard DS, Kristensen V, Perou CM, BorresenDale AL: Somatic sequence alterations in twenty-one genes selected by expression profile analysis of breast carcinomas. Breast Cancer Res 2007, 9:R5.

43. Bloushtain-Qimron N, Yao J, Snyder EL, Shipitsin M, Campbell LL, Mani SA, Hu M, Chen H, Ustyansky V, Antosiewicz JE, Argani P, Halushka MK, Thomson JA, Pharoah P, Porgador A, Sukumar S, Parsons R, Richardson AL, Stampfer MR, Gelman RS, Nikolskaya T, Nikolsky Y, Polyak K: Cell typespecific DNA methylation patterns in the human breast. Proc Natl Acad SciUSA 2008, 105:14076-14081.

44. Mani SA, Yang J, Brooks M, Schwaninger G, Zhou A, Miura N, Kutok JL, Hartwell K, Richardson AL, Weinberg RA: Mesenchyme Forkhead 1 (FOXC2) plays a key role in metastasis and is associated with aggressive basal-like breast cancers. Proc Natl Acad Sci USA 2007, 104:10069-10074.

45. Kalinina EV, Chernov NN, Saprin AN, Kotova YN, Remizov VI, Shcherbak NP: Expression of genes for redox-dependent glutathione S-transferase isoforms GSTP1-1 and GSTA4-4 in tumor cell during the development doxorubicin resistance. Bull Exp Biol Med 2007, 143:328-330.

46. Gilbert L, Elwood LJ, Merino M, Masood S, Barnes R, Steinberg SM, Lazarous DF, Pierce L, d'Angelo T, Moscow JA, et al:: A pilot study of piclass glutathione $\mathrm{S}$-transferase expression in breast cancer: correlation with estrogen receptor expression and prognosis in node-negative breast cancer. J Clin Oncol 1993, 11:49-58.

47. Huang J, Tan PH, Thiyagarajan J, Bay BH: Prognostic significance of glutathione S-transferase-pi in invasive breast cancer. Mod Pathol 2003, 16:558-565

48. Staalesen V, Knappskog S, Chrisanthar R, Nordgard SH, Lokkevik E, Anker G, Ostenstad B, Lundgren S, Risberg T, Mjaaland I, Gram IT, Kristensen VN, Borresen-Dale AL, Lillehaug JR, Lonning PE: The novel p21 polymorphism p21G251A is associated with locally advanced breast cancer. Clin Cancer Res 2006, 12:6000-6004.

49. Sorlie T, Johnsen H, Vu P, Lind GE, Lothe R, Borresen-Dale AL: Mutation screening of the TP53 gene by temporal temperature gradient gel electrophoresis. Methods Mol Biol 2005, 291:207-216.

50. Bergamaschi A, Kim YH, Wang P, Sorlie T, Hernandez-Boussard T, Lonning PE, Tibshirani R, Borresen-Dale AL, Pollack JR: Distinct patterns of DNA copy number alteration are associated with different clinicopathological features and gene-expression subtypes of breast cancer. Genes Chromosomes Cancer 2006, 45:1033-1040.

51. Tost J, Gut IG: DNA methylation analysis by pyrosequencing. Nat Protoc 2007, 2:2265-2275.

52. Akaike $\mathrm{H}$ : Information theory and extension of the maximum likelihood principle. Akademia Kiado, Budapest 1973:267-281.

doi: $10.1186 / 1476-4598-9-68$

Cite this article as: Dejeux et al., DNA methylation profiling in doxorubicin treated primary locally advanced breast tumours identifies novel genes associated with survival and treatment response Molecular Cancer 2010, 9:68 